\title{
Nylon-6/rubber blends: 7. Temperature- time effects in the impact behaviour of nylon/rubber blends
}

\author{
K. Dijkstra*, H. H. Wevers and R. J. Gaymans $\dagger$ \\ University of Twente, PO Box 217, 7500 AE Enschede, The Netherlands \\ (Received 11 March 1993; revised 11 June 1993)
}

\begin{abstract}
The deformation and fracture behaviour in notched tension of nylon-6/polybutadiene blends is studied as a function of strain rate and temperature. The sensitivity of the fracture behaviour to strain rate and temperature decreases with increasing rubber content. Unmodified nylon-6 can show ductile behaviour below $T_{\mathrm{g}}$, when the strain rate is sufficiently low. No discontinuous change in fracture energy is observed when passing the $T_{\mathrm{g}}$ of the matrix in the case where the fracture type is already ductile. The fracture energy appeared to decrease with increasing rubber content (tested in tension as well as tested with the Izod impact test) when the fracture type was ductile. In the case of ductile behaviour, fracture is preceded by massive yielding of the entire cross-section of the specimen.
\end{abstract}

(Keywords: nylon-rubber blend; impact behaviour; temperature-time effects)

\section{INTRODUCTION}

The temperature and strain-rate dependence of the mechanical behaviour of polymers is well known. In contrast with metals, which behave almost perfectly elastically, the deformation of polymers is partly elastic and partly viscous. The temperature and rate dependence of the two parameters most important for engineering applications, i.e. the modulus and the yield stress, have been studied extensively. It has been found that in many cases the effect of an increase in temperature is similar to the effect of a decrease in strain rate.

It is beyond the scope of this paper to give a review of the models used to describe this temperature-time equivalence. There is, however, no general theory describing temperature-time effects encountered in the mechanical behaviour of polymeric materials. Most of the models presented are only capable of predicting the temperature-time dependence of a single parameter (e.g. the position of the $\alpha$ transition or the yield stress) over a limited range of temperatures or rates.

At this moment the impact behaviour of polymeric multiphase systems is normally studied as a function of temperature. For rubber-toughened nylon- 6 an extensive study into the dependence of the impact strength on temperature and morphology was performed by Borggreve and coworkers ${ }^{1-4}$. It was shown that the impact strength of unmodified nylon only increased strongly at the glass transition temperature. When an elastomeric phase was blended in the nylon matrix the brittle-to-tough transition shifted to lower temperatures. This transition could not be associated with a transition in the mechanical behaviour of nylon or rubber. The brittle-to-tough transition temperature $\left(T_{\mathbf{B T}}\right)$ was found

* Current address: DSM Research, PO Box 18, 6160 MD Geleen, The Netherlands

† To whom correspondence should be addressed to be dependent on the rubber type ${ }^{4}$ and on the average distance between the rubber particles ${ }^{1,5}$.

In another publication the influence of the strain rate on the deformation and fracture of notched nylon-6/EPR (ethylene-propylene rubber) samples is discussed ${ }^{6}$. One of the most important conclusions was that a change in strain rate resulted not only in an increase in yield stress but also in a transition from isothermal to adiabatic deformation. It was proposed that under impact conditions the propagating crack is stabilized via the formation of a melt zone around the crack tip. From this point of view, the $T_{\mathbf{B T}}$ is the temperature above which the melt zone is formed.

Recently, Lazzeri ${ }^{7}$ performed three-point bend tests on nylon-6/EPR blends at low deformation speeds and under impact conditions. The data suggested that the critical interparticle distance has a different meaning at low speeds than under impact conditions, since the $T_{\mathrm{BT}}$ was independent of interparticle distance in the case of the low-speed tests.

The objective of the work presented in this paper is to investigate the temperature and rate dependence of the deformation and fracture behaviour of nylon/ rubber blends. For this reason nylon-6/polybutadiene (PA/BR) blends with different rubber concentrations were prepared. These blends were tested over a wide range of draw speeds and at five different temperatures. The test method used, the notched tensile impact (NTI) test, has been described elsewhere ${ }^{6}$.

\section{EXPERIMENTAL}

Test set-up

The test set-up for the notched tensile impact tests as described previously ${ }^{6}$ was adapted to make tests at temperatures other than room temperature possible (see Figure 1). A small isolation chamber (designed and 


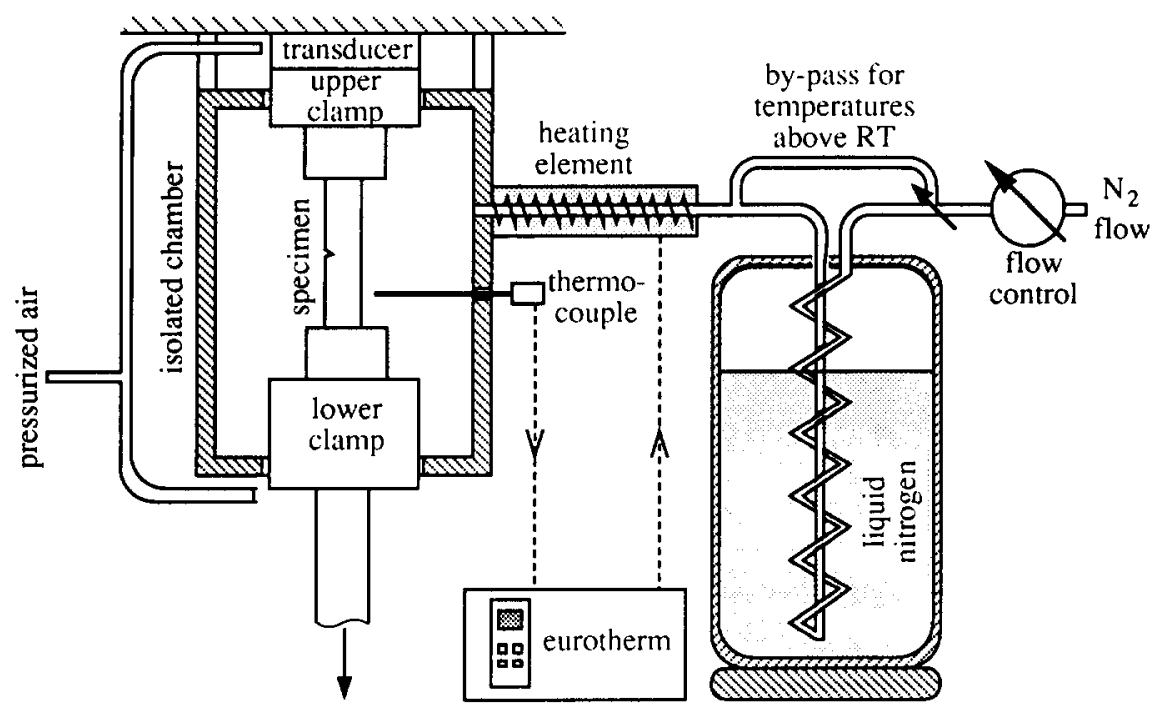

Figure 1 Test set-up for performing NTI tests at different temperatures

fabricated by Akzo) is mounted around the specimen. A nitrogen flow enters the isolation chamber via a heating element. The chamber temperature is measured by a thermocouple. By controlling the input power of the heating element with an Eurotherm controller, the chamber temperature can be brought to the desired value.

For temperatures below room temperature, the nitrogen flow first is cooled by liquid nitrogen and afterwards heated to the desired temperature. The nitrogen flow is controlled with a flow control unit. The force transducer is kept at room temperature by an air flow. There is also an air flow on the lower clamp in order to prevent ice deposition on the clamp and the pick-up unit.

Measurements were done at temperatures ranging from -40 up to $80^{\circ} \mathrm{C}$. In control experiments the temperature at the centre of the specimen was measured with a thermocouple. For all the test temperatures, within $10 \mathrm{~min}$ after closing the isolation chamber, the temperature inside the specimen had stabilized at the chamber temperature. Because of this, for all tests a time of $10 \mathrm{~min}$ was kept between closing the isolation chamber and performing the NTI test.

In the measurements presented in a previous publication $^{6}$ the slow-speed tests were performed on an Instron tensile tester. Since the isolation chamber was designed especially for the Schenck tensile tester and could not be mounted on the Instron, the slowspeed tests were also performed on the Schenck. The piezoelectric force transducer proved to give a constant output signal under a dead-load (comparable with the maximal force expected in the tests) over a time of at least $30 \mathrm{~min}$. Since the maximum test time is about $3 \mathrm{~min}$, the piezoelectric transducer was stable enough to be used for the slow speeds. Because the laser displacement system could not be used in the isolation chamber, the energies were calculated using the piston displacement signal. From the NTI test presented previously ${ }^{6}$, it appeared that the energies calculated with the piston displacement and those calculated with the clamp displacement were very similar.

\section{Materials}

A high-molecular-weight type nylon-6 (Akulon M258) supplied by Akzo was used; $\eta_{\text {rel }}$ in $96 \% \mathrm{H}_{2} \mathrm{SO}_{4}$ is $5.8, \rho$ is $1.14 \mathrm{~g} \mathrm{ml}^{-1}$ and $M_{\mathrm{n}}=35000 \mathrm{~g} \mathrm{~mol}^{-1}$.

The blend used was a commercial nylon-6/polybutadiene blend (Durethan BC303) supplied by Bayer. It has a rubber content of about $30 \mathrm{vol} \%$ polybutadiene and a weight-average particle size of $0.38 \mu \mathrm{m}$. Blends with a rubber content between 0 and 30 vol\% were prepared by diluting the Durethan BC 303 with the Akulon M258.

\section{Blend preparation and characterization}

Blends with a rubber content between 0 and $30 \mathrm{vol} \%$ were prepared on a Berstorff $\mathrm{ZE} 25$ co-rotating twin-screw extruder with a screw diameter of $25 \mathrm{~mm}$ and a $L / D$ of 33 . The BC 303 and the M258 were fed in the first zone with a total supply rate of $2 \mathrm{~kg} \mathrm{~h}^{-1}$. The barrel temperature was $260^{\circ} \mathrm{C}$ and the screw speed 100 rev min $^{-1}$.

The specimens (according to ISO 180/1A) were injection moulded on an Arburg Allrounder 221-55-250. The notch has been milled in the specimen. Before testing, the specimens were dried at $110^{\circ} \mathrm{C}$ under vacuum for $18 \mathrm{~h}$.

In order to determine particle size, particle size distribution and particle distribution, a sample was taken out of an injection moulded specimen. On this sample a smooth surface was prepared with a diamond knife on a CryoNova LKB 2285-050 microtome. The sample temperature during microtoming was $-110^{\circ} \mathrm{C}$.

From these samples the rubber was extracted from the microtomed surface by etching in boiling $m$-xylene for about $12 \mathrm{~h}$. After drying the samples at $110^{\circ} \mathrm{C}$ under vacuum for one night they were covered with a layer of gold and examined with a JEOL JSM-35CF scanning electron microscope. From the micrographs the particle size was determined.

Supplementary to the SEM studies, also some TEM studies were performed on the $15 \mathrm{vol} \%$ blend. In these studies the rubber is stained with $\mathrm{OsO}_{4}$. The preparation and the staining of the TEM samples is discussed elsewhere ${ }^{8}$.

\section{RESULTS AND DISCUSSION}

Blend morphology

In Table 1 the number-average rubber particle size $d_{\mathrm{n}}$ 
Table 1 Blend morphology of the prepared nylon-6/BR blends, as determined with SEM. The $15 \mathrm{vol} \%$ blend was also evaluated using TEM

\begin{tabular}{lllllll}
\hline \multicolumn{2}{c}{ Rubber content } & & & & \\
\cline { 1 - 2 }$(\mathrm{wt} \%)$ & $(\mathrm{vol} \%)$ & & $\begin{array}{l}d_{\mathrm{n}} \\
(\mu \mathrm{m})\end{array}$ & $\begin{array}{l}d_{\mathrm{w}} \\
(\mu \mathrm{m})\end{array}$ & $d_{\mathrm{w}} / d_{\mathrm{n}}$ & $\begin{array}{l}I D \\
(\mu \mathrm{m})\end{array}$ \\
\hline 0.8 & 1 & 0.28 & 0.33 & 1.18 & 0.90 \\
6.1 & 7.5 & 0.34 & 0.39 & 1.15 & 0.36 \\
12.1 & 15 & 0.34 & 0.39 & 1.14 & 0.20 \\
18.2 & 22.5 & 0.31 & 0.37 & 1.19 & 0.12 \\
24.2 & 30 & 0.34 & 0.38 & 1.12 & 0.08 \\
12.1 (TEM) & 15 (TEM) & 0.18 & 0.30 & 1.69 & 0.16 \\
\hline
\end{tabular}

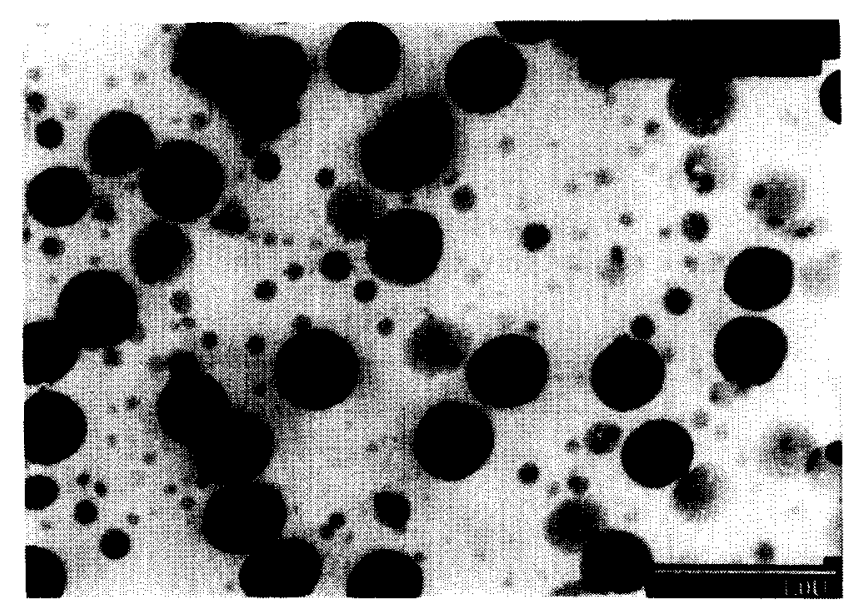

Figure 2 TEM micrograph of a $15 \mathrm{vol} \%$ nylon-6/polybutadiene (PA/BR) blend. The BR phase was stained with $\mathrm{OsO}_{4}$ (photo by H. Janik)

and the weight-average particle size $d_{w}$ are given for the prepared blends. It appeared that the distribution of the rubber particles in the Durethan blend as received was very inhomogeneous. Therefore, the master blend was extruded under the same extrusion conditions as the diluted blends. After this extrusion step the morphology was homogeneous.

The particle size did not change in the extrusion step. The interparticle distance $(I D)$ given in the last column is calculated according to the equation ${ }^{5}$ :

$$
I D=d\left[\left(\frac{\pi}{6 \varphi_{\mathrm{r}}}\right)^{1 / 3}-1\right]
$$

In Figure 2a TEM photograph is shown of the $15 \mathrm{vol} \%$ PA/BR blend. It can be seen that, despite the narrow distribution in particle size as measured from SEM micrographs, there are a large number of very small particles visible. In Table 1 , the particle size and particle size distribution as measured from TEM micrographs are given. The results indicate that with SEM, with a lower detection limit of $0.1 \mu \mathrm{m}$, the smallest particles present are not observed. These very small particles may be spheres or sections of large particles produced by microtoming. The number of these particles is too high to be sections of large particles. With SEM the particle size of these blends is overestimated.

\section{Notched Izod impact tests}

In Figure 3 the results of the notched Izod tests on the nylon-6/BR blends are given. Comparable tests on nylon-6/EPDM (ethylene-propylene-diene monomer) were carried out by Borggreve et al. ${ }^{1}$. They found that with increasing rubber content the $T_{\mathrm{BT}}$ decreased and the impact strength in the brittle as well as in the tough region increased. Also the impact strength in the brittle region appeared to increase with temperature; in the tough region it is not clear what the trend is.

These effects are only partly found for the nylon-6/BR blends. The $T_{\mathrm{BT}}$ decreases clearly with increasing rubber content. The level of impact strength in the tough region, however, decreases with increasing rubber content. Also the impact strength in the tough region tends to decrease with increasing temperature. Passing the $T_{\mathrm{g}}$ of the matrix does not affect the slope of this decrease when the blend breaks tough below $T_{\mathrm{g}}$. This is surprising since the impact strength of the unmodified nylon rises strongly when the temperature passes $T_{\mathrm{g}}$ (ref. 2).

Gaymans et al. ${ }^{9}$ proposed that incorporating a second elastomeric phase in a nylon matrix resulted in the introduction of two new transitions. From the data presented here it follows that probably only one new transition is introduced (at the $T_{g}$ of the rubber), while the transition at the $T_{\mathrm{g}}$ of the matrix is replaced by the transition at the $T_{\mathrm{BT}}$. The fact that specimens fractured above $T_{\mathrm{g}}$ of the matrix hardly show stress-whitening any more suggests that the mechanism responsible for the transition in impact strength at the $T_{\mathrm{BT}}$ differs from the one operative at the $T_{\mathrm{g}}$ of the matrix.

It was also found in the low-speed range of notched tensile impact tests done on nylon-6/EPR blends ${ }^{6}$ that the fracture energy decreases with increasing rubber content. It appears that, when the fracture behaviour is already ductile, an increase in rubber content only leads to a decrease of the stress level, and consequently in a decrease of fracture energy.

The results presented in Figure 3 differ in some aspects from the notched Izod impact strength of nylon-6/EPR blends with varying rubber concentration ${ }^{6}$. First, the $T_{\mathbf{B T}}$ is slightly lower for the nylon-6/polybutadiene blends. This is what might be expected since the cavitation stress of polybutadiene is lower than the cavitation stress of EPR ${ }^{4,10}$. The strong decrease in impact strength with temperature that could be observed with the nylon6/EPR blends is, however, less distinct in the data given in Figure 3. There are two possible explanations for this behaviour. First, the particle size of the PA/BR blends

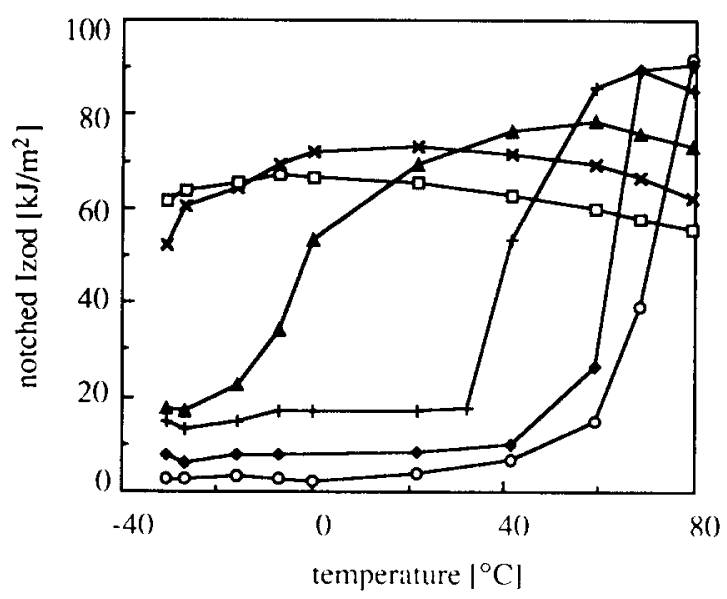

Figure 3 Notched Izod versus temperature for nylon-6/BR blends with a constant particle size (Table $I$ ) and varying rubber content. Rubber volume fraction: $(\mathrm{O}) 0.00,(\bullet) 0.01,(+) 0.075,(\boldsymbol{A}) 0.15,(\times) 0.225$, (口) 0.30 


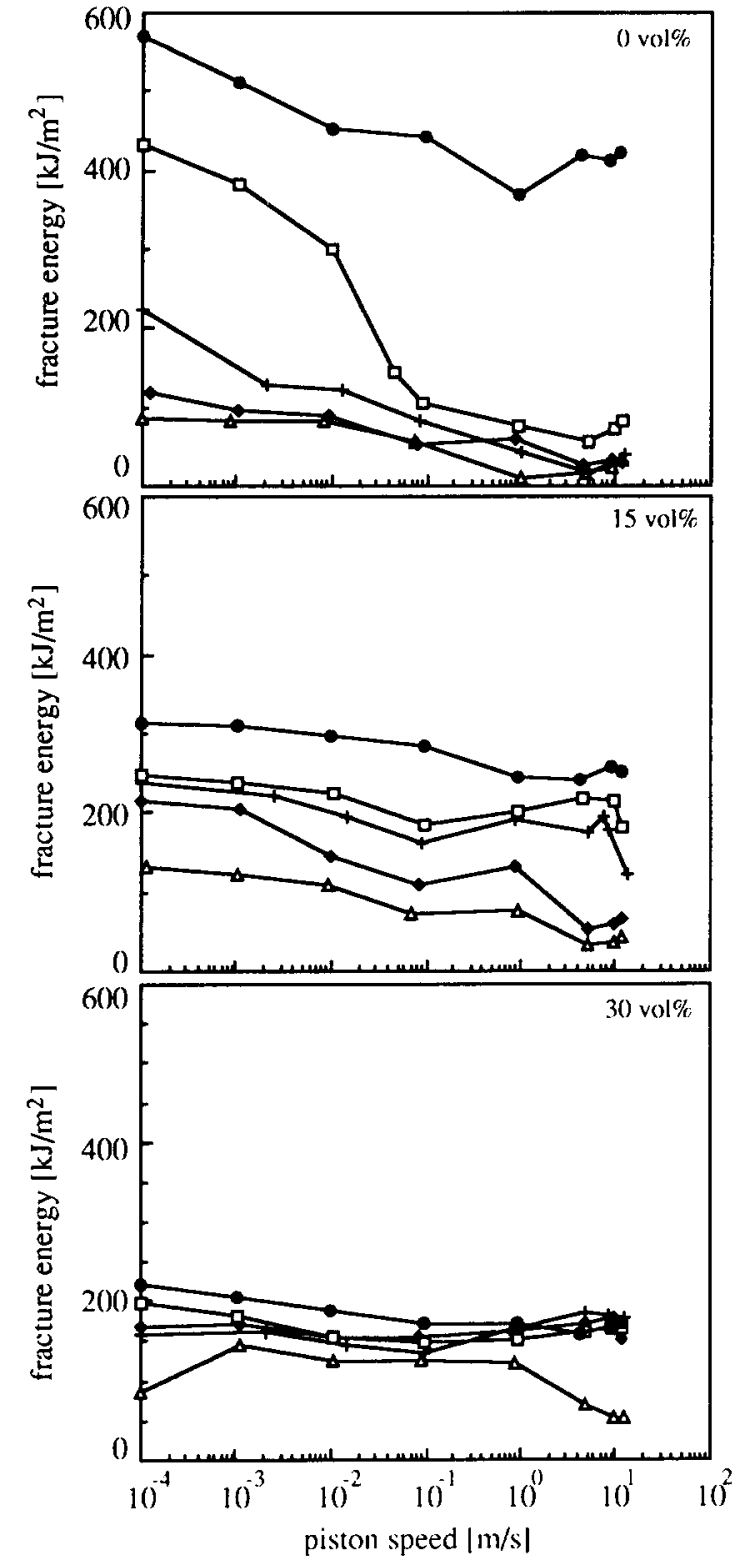

Figure 4 Fracture energy versus piston speed with different test temperatures: $(\triangle)-40^{\circ} \mathrm{C},(\bullet)-10^{\circ} \mathrm{C},(+) 20^{\circ} \mathrm{C},(\square) 50^{\circ} \mathrm{C},(\odot) 80^{\circ} \mathrm{C}$

is less critical because of the low cavitation stress of BR. Secondly, the particle size distribution is narrower in the case of the PA/BR blends.

\section{Notched tensile impact tests}

In Figures 4-7 (the upper graphs) the results of the NTI tests on unmodified high-molecular-weight nylon- 6 with varying test temperature are given. For the two lowest temperatures $\left(-40\right.$ and $\left.-10^{\circ} \mathrm{C}\right)$ the fracture type is brittle over the complete range studied. At room temperature a tough-to-brittle transition is visible between a piston speed of $10^{-4}$ and $10^{-3} \mathrm{~m} \mathrm{~s}^{-1}$ (Figure 7). At a test temperature of $50^{\circ} \mathrm{C}$ this transition has shifted to a higher strain rate (piston speed between $10^{-2}$ and $5 \times 10^{-2} \mathrm{~m} \mathrm{~s}^{-1}$ ), and above the $T_{\mathrm{g}}$, all the specimens break in a tough fashion.

When the test temperature is below $T_{\mathrm{g}}$ and the fracture type is tough, stress-whitening can be seen ahead of the notch. With increasing test temperature the size of the stress-whitened zone decreases; in all cases stresswhitening is not observed over more than half of the fracture surface. Above $T_{\mathrm{g}}$ of the matrix no stresswhitening is visible any more. The specimens, however, show signs of very ductile behaviour.

In general, the PA/BR blends show similar behaviour. The fracture type is ductile for test temperatures of $20^{\circ} \mathrm{C}$ and higher. The $15 \mathrm{vol} \%$ blend shows at $-10^{\circ} \mathrm{C}$ a transition from ductile to brittle between a test speed of $10^{-3}$ and $10^{-2} \mathrm{~m} \mathrm{~s}^{-1}$, and is brittle for all strain rates tested at $-40^{\circ} \mathrm{C}$. The $30 \mathrm{vol} \%$ blend is ductile at $-10^{\circ} \mathrm{C}$. A remarkable point is that at $-40^{\circ} \mathrm{C}$ two brittle-to-tough transitions are visible. At the lowest test speed and for piston speeds above $1 \mathrm{~m} \mathrm{~s}^{-1}$ the behaviour is brittle. For the intermediate draw speeds the specimens fail in a ductile fashion. When no transitions from brittle to tough are encountered, the fracture energy is hardly dependent on strain rate.

It was demonstrated that, when the fracture energy of nylon-6/EPR blends was plotted against the test speed, a minimum at intermediate test speeds $\left(10^{-2} \mathrm{~m} \mathrm{~s}^{-1}\right)$ was observed $^{6}$. A similar minimum, but less pronounced, is visible in the propagation energy of the $15 \mathrm{vol} \%$ blend. Independent of the test temperature the propagation

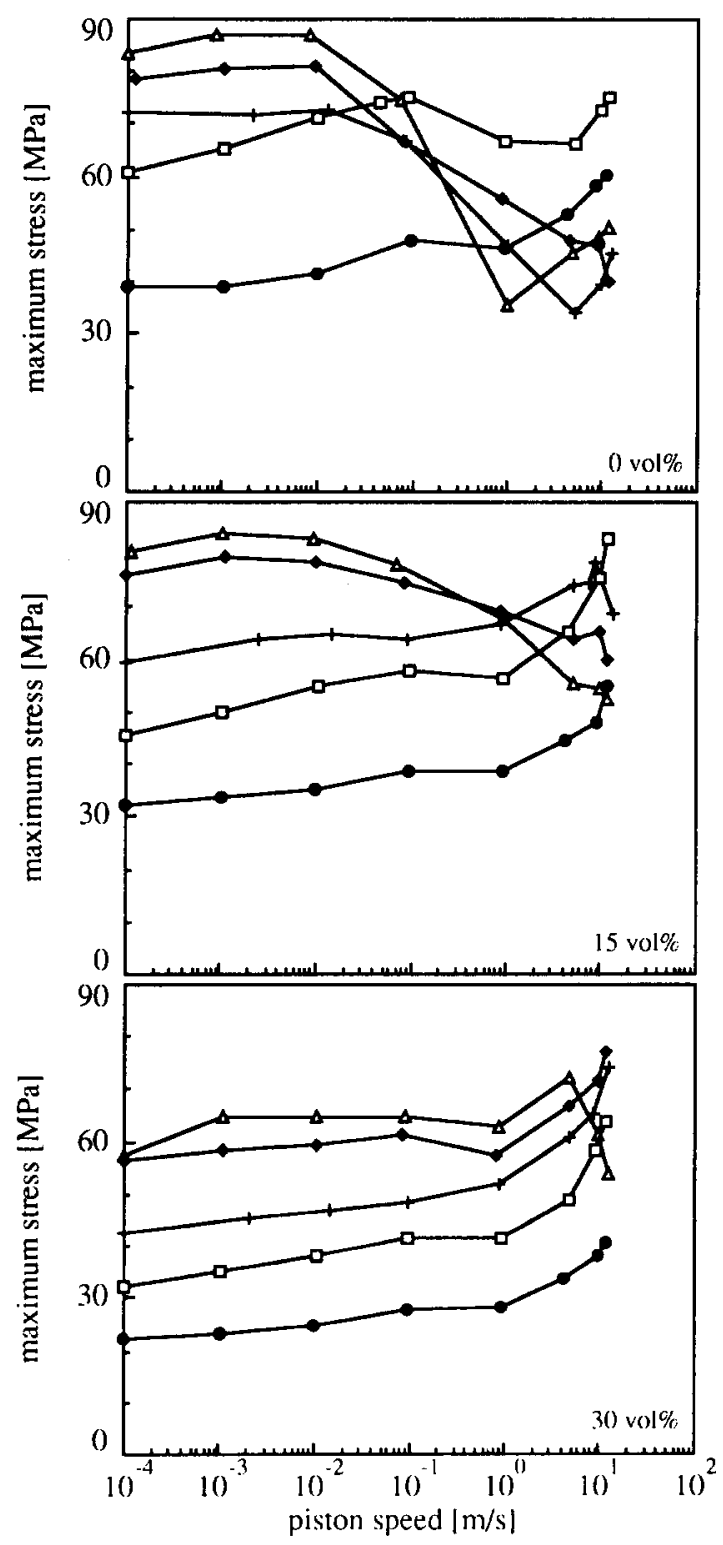

Figure 5 Maximum stress versus piston speed with different test temperatures: $(\triangle)-40^{\circ} \mathrm{C},(\diamond)-10^{\circ} \mathrm{C},(+) 20^{\circ} \mathrm{C},(\square) 50^{\circ} \mathrm{C},(\odot) 80^{\circ} \mathrm{C}$ 


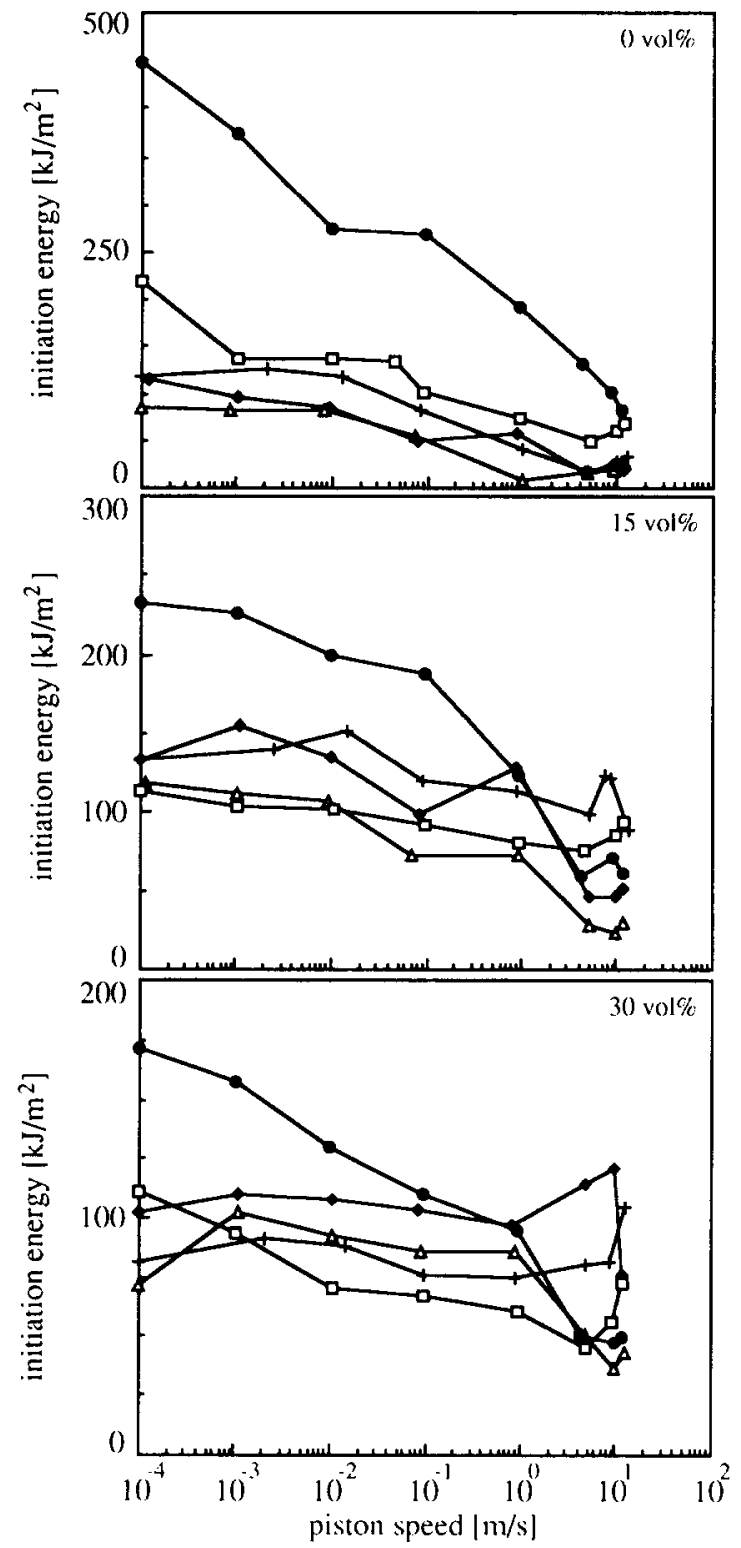

Figure 6 Initiation energy versus piston speed with different test temperatures: $(\triangle)-40^{\circ} \mathrm{C},(\triangle)-10^{\circ} \mathrm{C},(+) 20^{\circ} \mathrm{C},(\square) 50^{\circ} \mathrm{C},(\odot) 80^{\circ} \mathrm{C}$

energy starts to rise above a test speed of $10^{-1} \mathrm{~m} \mathrm{~s}^{-1}$. The $30 \mathrm{vol} \%$ blends show the same rise in propagation energy above a test speed of $10^{-1} \mathrm{~m} \mathrm{~s}^{-1}$, but the minimum is hardly visible any more.

When the fractured specimens are observed, the tough fractured samples show large triangular-shaped stress-whitened zones. When the test speed was low, macroscopic necking of the specimens could be observed. For the higher speeds a thin layer with the colour of the undeformed material could be observed. This layer was better observed with increasing test speed and test temperature. When the test temperature was above $T_{\mathrm{g}}$ the fractured specimens hardly showed stress-whitening any more.

\section{The fracture energy}

When the fracture energy versus test speed and test temperature is observed, it is clear that the sensitivity to both parameters decreases with increasing amount of rubber. In Figure 8 the fracture energy is plotted versus the test temperature for two different test speeds. For the low piston speed, the brittle-to-tough transition is hardly visible as a discontinuous change in the fracture energy. It is also evident that for this piston speed passing the glass transition does not result in a discontinuous change in fracture energy for all materials.

For the high piston speeds, the $T_{\mathrm{g}}$ seems to play an important role. The unmodified nylon breaks in a tough manner for all the test speeds when the test temperature is above $T_{\mathrm{g}}$. This indicates that with low speeds the $T_{\mathrm{BT}}$ can be lower than the glass transition temperature but that with increasing test speed the $T_{\mathrm{g}}$ is an upper limit for $T_{\mathrm{BT}}$. When the blends are observed it appears that, despite the fact that the $T_{\mathrm{g}}$ can play an important role in the transition from brittle to tough behaviour, the level of the fracture energy does not change discontinuously when passing the $T_{\mathrm{g}}$ in the case where the fracture type already is ductile.

When the results obtained with the NTI test are compared with the notched Izod results in Figure 3, it is clear that the fracture energy in tensile loading is considerably higher than the fracture energy of the same material in bending (Izod). In Figure 9 the ratio between

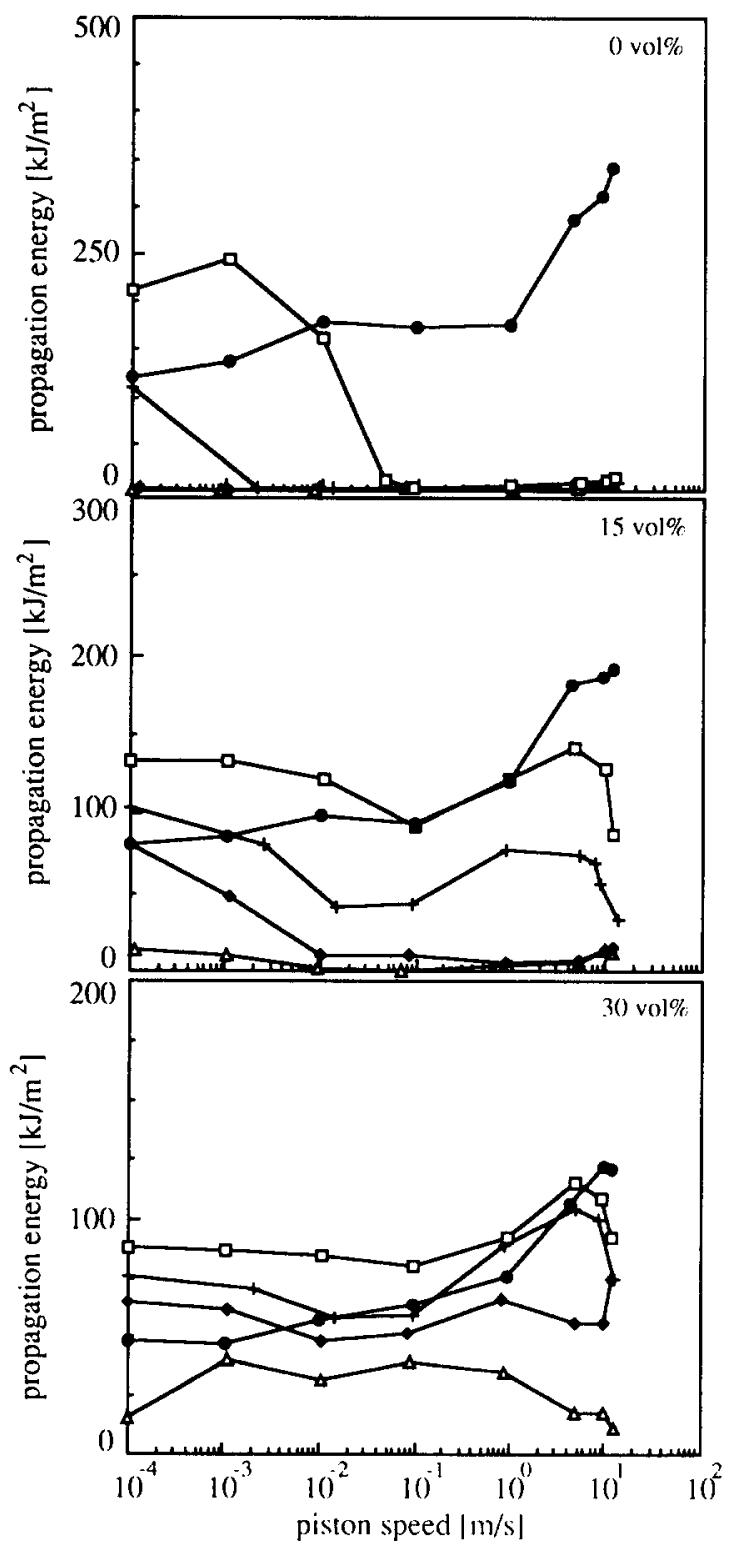

Figure 7 Propagation energy versus piston speed with different test temperatures: $(\triangle)-40^{\circ} \mathrm{C},(\triangleleft)-10^{\circ} \mathrm{C},(+) 20^{\circ} \mathrm{C},(\square) 50^{\circ} \mathrm{C},(\bigcirc) 80^{\circ} \mathrm{C}$ 

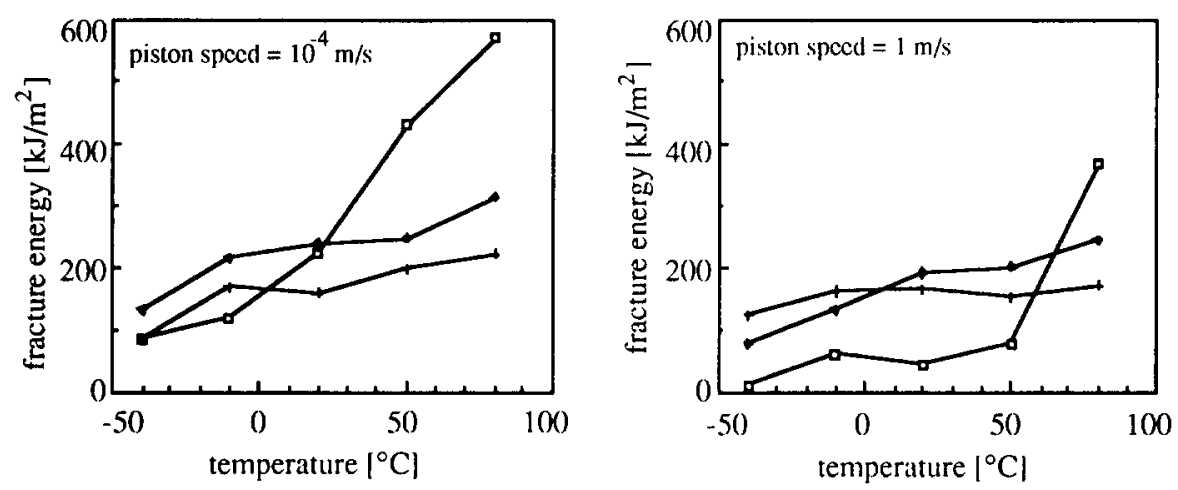

Figure 8 Fracture energy versus temperature as measured with the NTI test for two different piston velocities. Rubber concentration: $(\square) 0 \mathrm{vol} \%,(\bullet) 15 \mathrm{vol} \%,(+) 30 \mathrm{vol} \%$

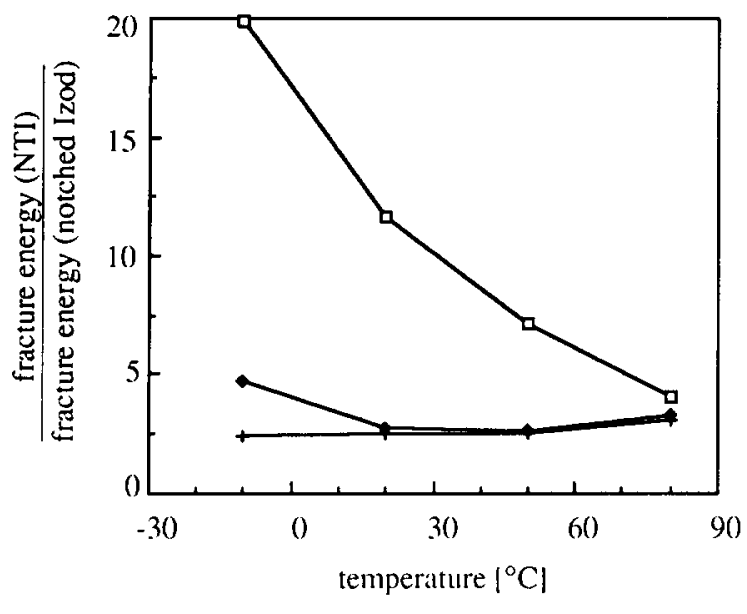

Figure 9 The ratio between the fracture energy measured with the NTI test (piston speed is $1 \mathrm{~m} \mathrm{~s}^{-1}$ ) and the impact strength measured with the notched Izod versus the test temperature. Rubber concentration: $(\square) 0 \mathrm{vol} \%,(+) 15 \mathrm{vol} \%,(+) 30 \mathrm{vol} \%$

the fracture energy of the two test methods is given versus the test temperature. The test speed used in the NTI tests is taken as $1 \mathrm{~m} \mathrm{~s}^{-1}$, which is approximately the test speed of the notched Izod.

It appears that, when the samples fracture in a tough manner, the ratio between the two fracture energies is more or less a constant $(\approx 2.5)$ and independent of the rubber content. Only when the test temperature is above $T_{\mathrm{g}}$ does the ratio increase slightly. When, however, the fracture is brittle, the ratio is much higher and can reach a factor of 20 in the case of pure nylon. This is caused by the fact that in the NTI test the initiation and propagation energy are of the same order of magnitude. Therefore, the drop in fracture energy when the fracture type changes from tough to brittle will be less strong in the NTI test than in an Izod test. The fact that the notched Izod shows such strong effects when going from a brittle to a tough fracture indicates that the level of the notched Izod is dominated by the propagation energy.

The difference in fracture energy between the two tests in the case of a tough fracture is partly caused by the differences in the size of the deformation zone and partly by the fact that during an NTI test a larger part of the specimen takes part in the elastic deformation.

When comparing the fracture energy measured with the notched Izod and with the NTI test, besides the level of impact strength the transition from brittle to tough behaviour is also important. In the NTI test the transition

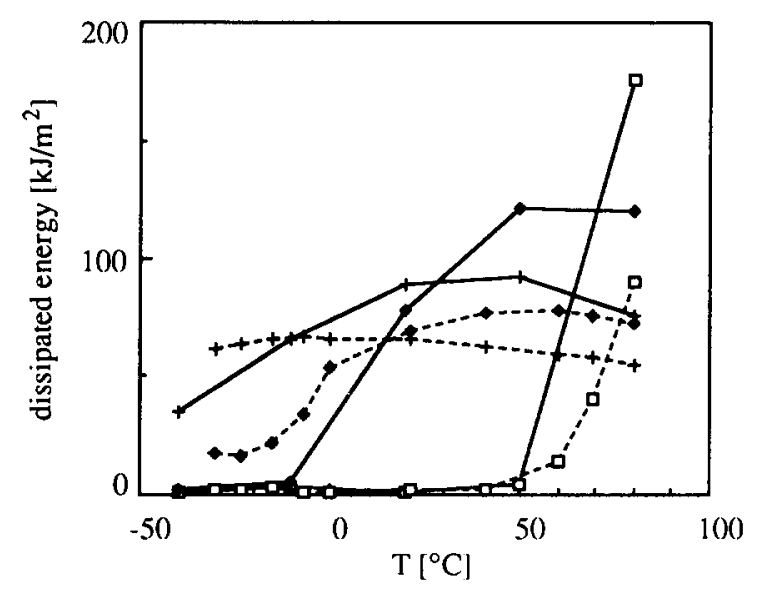

Figure 10 Comparison of the Izod impact test and the NTI test for nylon-6/BR blends with varying rubber content: $(\square) 0$ vol\%, (৬) $15 \mathrm{vol} \%,(+) 30 \mathrm{vol} \% ;(-)$ crack propagation energy measured with the NTI test (piston speed is $\left.1 \mathrm{~m} \mathrm{~s}^{-1}\right) ;(---)$ measured with the notched Izod impact test

from brittle to tough is visible most clearly in the propagation energy. Therefore, the propagation energy and the notched Izod versus temperature are plotted in Figure 10. Again there are differences between the actual values measured but the transitions are at the same place for all the materials tested.

From this it can be concluded that results obtained with the two different tests are qualitatively comparable. The levels in fracture energy may differ, however, especially when the fracture type is brittle.

\section{The maximum stress}

Generally speaking, when the material shows ductile or semi-brittle behaviour, the maximum stress increases slightly with increasing test speed. A transition from semi-brittle to brittle behaviour is characterized by a strong drop in the maximum stress for the unmodified nylon and by a slow decrease for the rubber-toughened materials. When no transitions are encountered, the maximum stress decreases approximately linearly with increasing test temperature.

It was demonstrated in a previous publication that the maximum stress for nylon- 6 correlated with the yield stress of the nylon (as measured in unnotched samples) in the case where the fracture was semi-brittle ${ }^{6}$. In Figures 11 and 12 the yield stress as measured in a standard tensile test and the maximum stress measured 
with the NTI test are given versus strain rate and test temperature respectively for the two blends.

There is a good correlation between the maximum stress and the yield stress of the blends. Only for a test

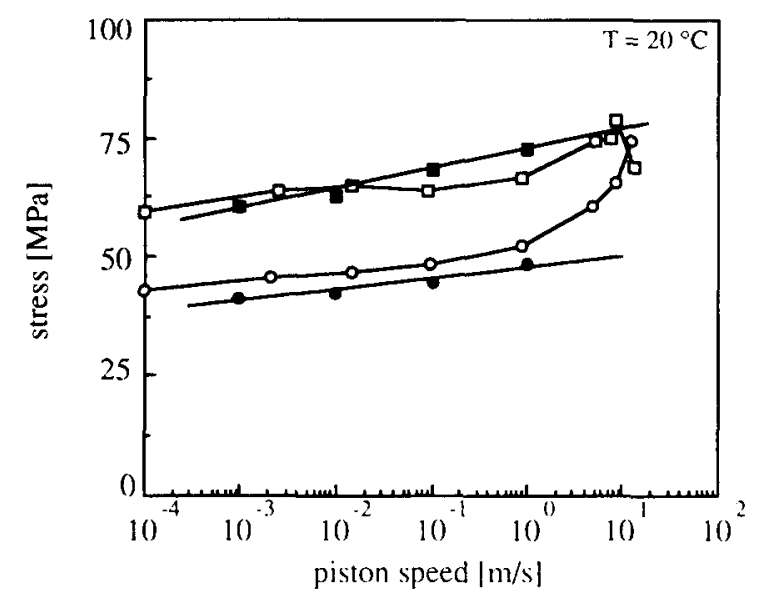

Figure 11 The maximum stress as measured in the NTI test compared with the yield stress as measured with a standard tensile test versus the piston speed: ( $\square$ ) yield stress, 15 vol\%; ( $\square$ ) maximum stress, 15 vol\%; (O) yield stress, $30 \mathrm{vol} \%$; $(O)$ maximum stress, $30 \mathrm{vol} \%$

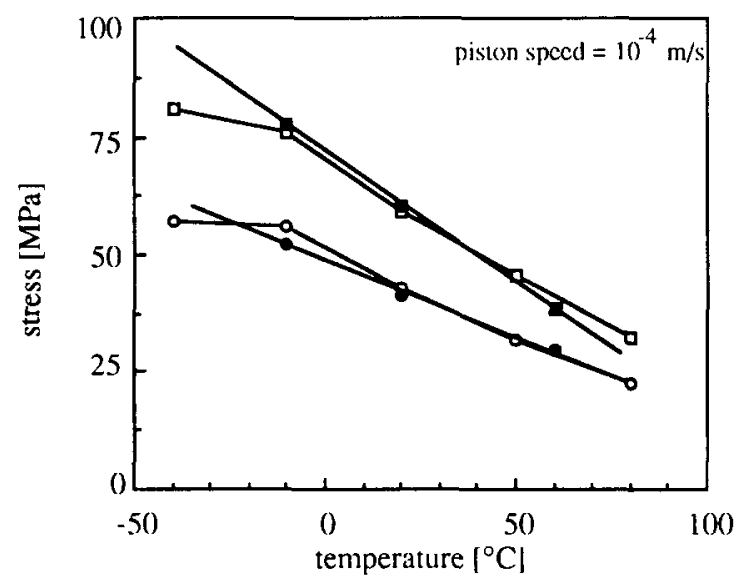

Figure 12 The maximum stress as measured in the NTI test compared with the yield stress as measured with a standard tensile test versus the test temperature: $(\boldsymbol{D})$ yield stress, $15 \mathrm{vol} \%$; ( $\square$ ) maximum stress, $15 \mathrm{vol} \%$; (O) yield stress, $30 \mathrm{vol} \% ;(\bigcirc)$ maximum stress, $30 \mathrm{vol} \%$ temperature of $-40^{\circ} \mathrm{C}$, where both blends fracture in a brittle way, is the yield stress significantly higher than the maximum stress. This means that also for tough behaviour the stress level is determined by the yield stress of the system.

When the blend is tough over the entire speed range, the maximum stress suddenly shows a sharp increase above $1 \mathrm{~m} \mathrm{~s}^{-1}$, where the yield stress keeps increasing approximately logarithmically with test speed. This behaviour was also found for nylon-6/EPR blends ${ }^{6}$. It was suggested that under adiabatic conditions the temperature in the notch may rise strongly. In this way, the notch tip radius can be blunted and crack initiation can be postponed.

\section{Initiation and propagation energy}

It was demonstrated that maximum stress reached in an NTI test is correlated with the yield stress if the specimen fails in a ductile manner. Owing to stress concentration, yielding will be possible close to the notch in an earlier stage. The point where the crack is initiated is still a point of discussion. Therefore, the division of the fracture energy into an initiation and a propagation part is somewhat arbitrary.

In the case of a brittle fracture the division between initiation and propagation is not ambiguous. At the point of maximum stress the stress drops almost instantaneously to zero and the propagation energy is close to zero. When, however, the material behaves in a tough manner, large-scale plasticity over a large part of the future crack plane is possible. This means that the ratio of initiation and propagation is strongly dependent on the point where the crack is initiated. This ratio can, therefore, vary strongly while the sum of the initiation and propagation energy stays fairly constant.

This effect is demonstrated in Figure 13 where the stress-displacement curves are given for nylon- 6 deformed at a test temperature of $80^{\circ} \mathrm{C}$ with different draw speeds, together with the division of the fracture energy into an initiation and a propagation part. The total fracture energy does not vary much over the test speed range. For the low speeds, however, the largest portion of the energy is dissipated before the crack starts running, while in the high-speed region most of the energy is dissipated during crack propagation.
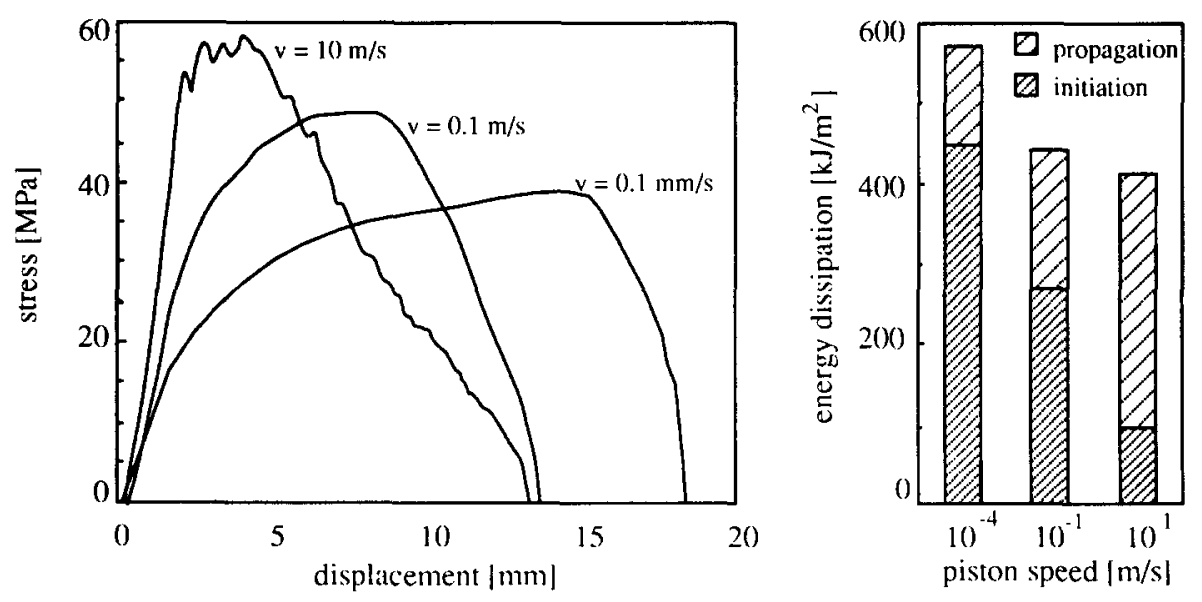

Figure 13 Stress-displacement curves for $\mathrm{M} 258$, measured at $80^{\circ} \mathrm{C}$ for different piston speeds. The histogram gives the division of the fracture energy into the initiation and the propagation energy 

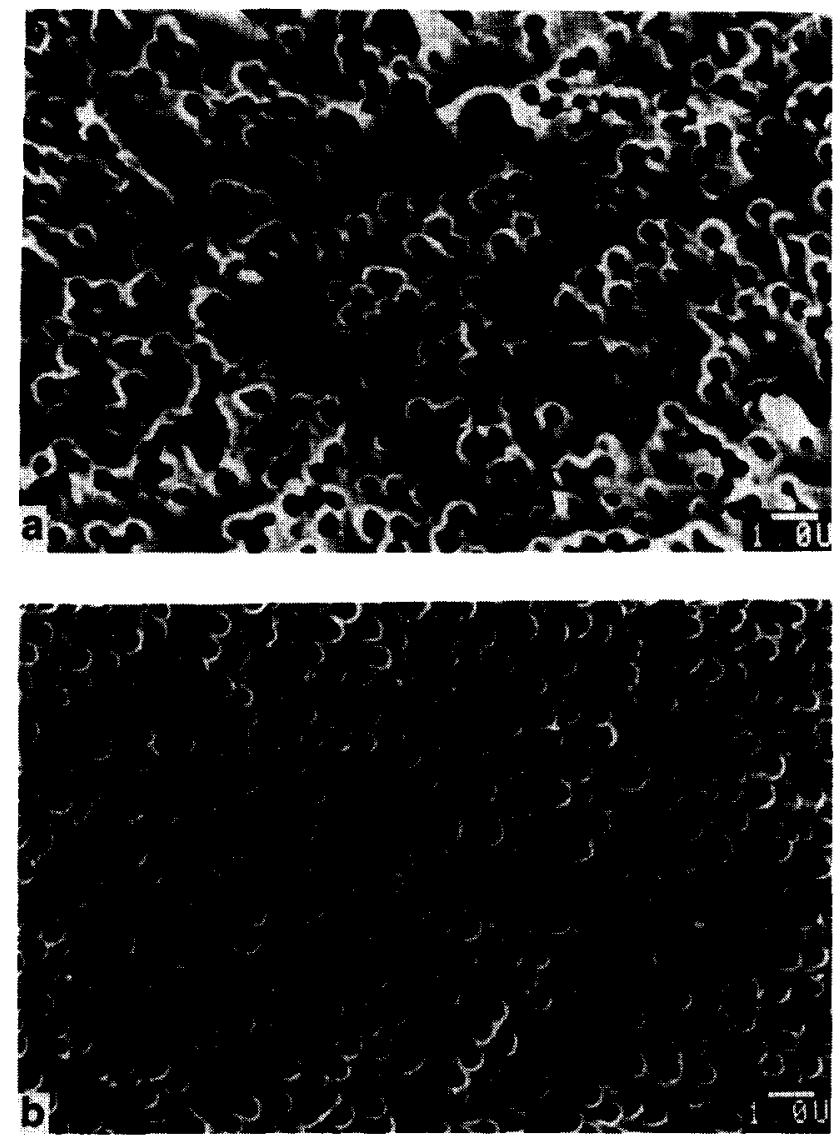

Figure 14 Morphology of the master blend nylon-6/BR (30 vol\%): (a) as delivered; (b) after extrusion

\section{Influence of the homogeneity of the blend morphology}

It has been mentioned in the previous part of this paper that the master blend as delivered had a very poor distribution of the rubber particles in the matrix. This distribution could be improved strongly by extruding the material under the conditions mentioned in the above section. In Figure 14 SEM micrographs of the morphology before and after extrusion are shown.

The samples used for the SEM studies are taken from the injection-moulded specimens used for the NTI tests described below. It is clear that the material as delivered shows clustered particles and particles lying in interconnected rows. After extrusion the particle clusters have disappeared. There are, though, still a number of particle rows visible. This means that the distribution is not yet completely homogeneous.

In Figure 15 the results of the NTI tests are given. Despite the very poor distribution, the as-received and the extruded blend show the same behaviour over a large range of deformation rates. Only when the draw speed is increased above $2 \mathrm{~m} \mathrm{~s}^{-1}$ does the as-received blend have a transition from tough to brittle behaviour while the extruded blend remains tough over the entire speed range studied.

Therefore, it appears that the homogeneity of the distribution of the particles only affects the brittle-totough transition and that the level of fracture energy in the case where the fracture is tough is not a function of the homogeneity. This suggests that the poor distribution results in an enlargement of the average interparticle distance.

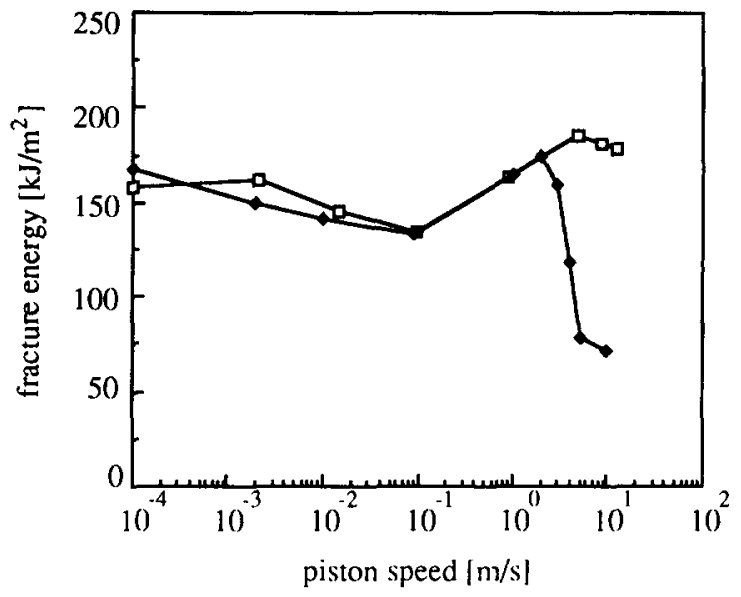

Figure 15 Fracture energy as measured with the NTI test for Durethan BC303: ( ) BC303 as delivered; ( $\square$ ) BC303 after extrusion

\section{CONCLUSIONS}

Temperature and strain rate have a strong effect on the fracture energy of unmodified nylon. With changing temperature as well as with changing strain rate, brittle-to-tough transitions can be found. It is not necessary for the pure nylon to be above $T_{\mathrm{g}}$ to behave in tough fashion when the strain rate is low enough. However, the $T_{\mathrm{g}}$ seems to be an upper limit for the $T_{\mathrm{BT}}$. Below $T_{\mathrm{g}}$, also unmodified nylon forms a stress-whitened zone when it fractures in a tough manner. This suggests that also in the homopolymer a voiding mechanism is operative.

The fracture energy does not change discontinuously when the $T_{\mathbf{g}}$ of the matrix is passed when the fracture type is already tough. This is the case for the blends as well as for the unmodified nylon. Therefore, a rubbertoughened nylon only shows two transitions in toughness versus temperature.

When the fracture type is tough, the impact strength clearly decreases when the rubber volume fraction is increased. This effect is measured in notched Izod tests and in NTI tests. Also the fracture energy decreases with temperature in the tough region. From this it can be concluded that, when the yield stress is low enough for ductile behaviour, a further decrease of the yield stress will result in a decrease of the fracture energy.

With increasing rubber content the sensitivity of the fracture mechanism of blends to temperature and strain rate decreases. For all the blends the $T_{\mathrm{BT}}$ was below $20^{\circ} \mathrm{C}$ over the entire speed range tested and there seemed to be no correlation between $T_{\mathrm{BT}}$ and the $T_{\mathrm{g}}$ of the matrix.

In case of tough behaviour, the maximum stress reached during an NTI test is determined by the yield stress of an unnotched sample. Only when the test speed is above $1 \mathrm{~m} \mathrm{~s}^{-1}$ does the maximum stress increase more than the yield stress. This is probably caused by postponed crack initiation due to an adiabatic temperature rise.

The NTI test performed with a draw speed of $1 \mathrm{~m} \mathrm{~s}^{-1}$ yields qualitatively similar results as the notched Izod. The transitions from brittle to tough are not shifted and the ratio of the fracture energy in the tough region obtained with the two test methods is fairly constant. However, when the fracture type is brittle the ratio rises strongly, owing to the high brittle fracture energy in an NTI test. 
The NTI tests on nylon-6/BR blends with different homogeneities demonstrate that a poor distribution of the rubber particles in the nylon matrix only affects the brittle-to-tough transition. In the case of tough behaviour, the fracture energy is not affected by the homogeneity of the blend.

\section{ACKNOWLEDGEMENTS}

We would like to thank Prof. Dr. Ir. L. C. E. Struik for helpful discussions. We are also grateful to Helena Janik for assistance with the TEM studies. This work is part of the research programme of the University of Twente and was financially supported by the SON/STW.

\section{REFERENCES}

1 Borggreve, R. J. M., Gaymans, R. J., Schuijer, J. and Ingen Housz, J. F. Polymer 1987, 28, 1489

2 Gaymans, R. J., Borggreve, R. J. M. and Spoelstra, A. B. J. Appl. Polym. Sci. 1989, 37, 479

3 Borggreve, R. J. M. and Gaymans, R. J. Polymer 1989, 30, 63

4 Borggreve, R. J. M., Gaymans, R. J. and Schuijer, J. Polymer 1989, 30, 71

Wu, S. Polymer 1985, 26, 1855

6 Dijkstra, K., ter Laak, J. and Gaymans, R. J. Polymer 1994, 35, 315

7 Lazzeri, A., PhD Thesis, Cranfield Institute of Technology, UK, 1991

8 Janik, H., Dijkstra, K. and Gaymans, R. J., to be published

9 Gaymans, R. J., Oostenbrink, A. J. and Borggreve, R. J. M. Makromol. Chem., Macromol. Symp. 1990, 38, 125

10 Dijkstra, K., Oostenbrink, A. J. and Gaymans, R. J. PRI Conf., Cambridge, 1991, Paper 39 